\title{
A CONTRIBUIÇÃO DO IBGE PARA AS LEITURAS DO TERRITÓRIO NACIONAL NA PERSPECTIVA DA METROPOLIZAÇÃO DO ESPAÇO
}

Olga Lúcia Castreghini de Freitas-Firkowski

Universidade Federal do Paraná

Resumo

\begin{abstract}
O texto trata da importância de alguns estudos recentes oferecidos pelo IBGE e selecionados pelo fato de contribuírem para uma leitura do território nacional desde o processo de metropolização do espaço. Ressalta a necessidade de novas ferramentas analíticas capazes de capturar a realidade atual e o papel fundamental do IBGE no oferecimento de bases de dados que favorecem essa tarefa.
\end{abstract}

Palavras-chave: Metropolização; espaço; IBGE; base de dados; território

\begin{abstract}
The text deals with the importance of some recent studies offered by IBGE and selected because they contribute to a reading of the national territory since the process of space metropolization. It emphasizes the need for new analytical tools capable of capturing the current reality and the fundamental role of IBGE in providing databases that favor this task.
\end{abstract}

Key words: Metropolization; space; IBGE; data base; territory.

A

s transformações que caracterizam a sociedade nesse momento da história se revelam nas formas como espaços são produzidos e ocupados. A crescente concentração da população em grandes cidades altera modos e práticas de vida, que se reproduzem por toda a rede urbana, naturalizando elementos que passam a fazer parte do cotidiano das pessoas.

O ritmo da vida nas grandes cidades dita o ritmo das demais, estruturas criadas para atender as demandas da vida metropolitana se disseminam e alteram as características dos lugares. A mobilidade é um fator-chave da vida moderna, seja na dimensão interurbana seja na dimensão intraurbana, em especial em razão da crescente dimensão territorial alcançada pelas cidades, cujos limites são cada vez mais imprecisos e distantes.

Apreender essa realidade como objeto de análise desde a Geografia, requer a existência de fontes confiáveis e abrangentes de informação, que possibilitem uma uniformização no sentido atribuído aos dados e a certeza de que os mesmos parâmetros são utilizados para a produção da informação.

Tal tarefa não pode ser de responsabilidade individual de cada pesquisador, muito embora tenhamos os estudos de caso e a produção de informações primárias como características de 
parte dos trabalhos acadêmicos realizados no âmbito da Geografia, informações totalizantes sobre a realidade, na maior parte das vezes, estão fora do alcance do pesquisador, tendo em vista a amplitude das mesmas.

Leituras sobre o território, em particular num país com as dimensões do Brasil, exigem constante aprimoramento metodológico e observação atenta e sistemática da realidade, tarefa que tem sido cumprida de modo competente pelo IBGE ao longo de sua existência.

A produção de uma gama de informações e, em especial, de séries históricas que possibilitem a comparação no tempo e no espaço, garantem aos pesquisadores uma fonte segura e confiável de obtenção de dados e interpretações da realidade. Por isso, qualquer ameaça à continuidade dos trabalhos do IBGE ou mesmo à mudança de metodologias e bases de dados são preocupantes e devem ser objeto de minuciosa ponderação.

O principal produto do IBGE é, sem dúvida, o Censo Demográfico, cujas informações são coletadas a cada 10 anos. Tais informações são fundamentais para caracterizar a sociedade contemporânea e revelar as mudanças havidas ao longo do tempo, em especial acerca de tendências demográficas de distribuição da população e do perfil socioeconômico, com informações sobre renda, escolaridade, situação de moradia, relações de parentesco, composição familiar, dentre outras características do morador, além disso, também são coletadas informações sobre as características do domicílio, como o material construtivo, os bens existentes, a responsabilidade pelo domicílio, dentre outras.

No que concerne aos estudos urbanos, salienta-se a relevância da informação relativa ao movimento pendular, que captura dados sobre os deslocamentos das pessoas que moram em um determinado município e se deslocam para trabalhar ou estudar em outro. Essa informação é de grande importância para o mapeamento dos deslocamentos das populações e o reconhecimento de áreas urbanas com grande integração interna e sobre as quais é imperativo propor políticas públicas abrangentes.

Embora o Censo Demográfico seja o produto mais conhecido do IBGE, uma variedade de estudos sobre o território é também produzida pelo Instituto e disponibilizada para consulta em seu portal. Aqui reside outro elemento importante a ser ressaltado: a maioria absoluta das bases de dados e os estudos são de acesso aberto, facilitando sua utilização por pesquisadores de diferentes níveis de formação e por pesquisas muitas vezes não financiadas, em especial aquelas realizadas por mestrandos e doutorandos nos diversos programas de pós-graduação em Geografia existentes no país.

Dentre eles, são de particular interesse à Geografia no contexto das análises urbanometropolitanas os seguintes eixos e seus detalhamentos sobre Organização do Território: Estrutura territorial, Divisão regional, Análises do território, Tipologias do território e Redes e fluxos geográficos.

O objetivo do presente texto não é o de inventariar a produção do IBGE, mas de realçar algumas possibilidades de utilização de estudos específicos à luz da discussão urbanometropolitana na atualidade.

Dessa forma, queremos ressaltar um grupo de estudos, a seguir identificados: i) Regiões de influência das cidades (REGIC); ii) Divisão Urbano-Regional, aprofundada nos estudos Divisão 
Regional do Brasil em Regiões Geográficas Imediatas e Regiões Geográficas Intermediárias; Regiões Ampliadas de Articulação Urbana; iii) Arranjos populacionais e concentrações urbanas do Brasil; iv) Classificação e caracterização dos espaços rurais e urbanos do Brasil. Uma primeira aproximação.

Tais estudos convergem para a preocupação central desse texto, que é a de evidenciar as possibilidades de novas leituras do território decorrentes do processo de metropolização em curso. Ora tratam de dinâmicas regionais à luz da dimensão urbano-metropolitana, ora tratam da dimensão intraurbana. Apontam importantes transformações, em especial na configuração espacial desses espaços e a eles atribuem novas denominações.

Aí reside sua relevância tanto para as pesquisas quanto para a formação, em especial de geógrafos, capazes de interpretar os processos urbano-metropolitanos em curso em nosso país.

\section{A metropolização do espaço: elementos teóricos}

A apreensão teórica do mundo metropolitano, ou seja, do mundo perpassado e definido a partir do processo de metropolização em curso, tem sido objeto de análise de diversos autores.

Soja (2013, p. 138), afirma que o protagonismo das metrópoles no mundo atual, relacionase diretamente ao movimento que denominou de "virada espacial", e que a "causalidade espacial urbana", provoca uma transformação completa nos esquemas teóricos de interpretação da realidade atual, ressaltando que os espaços urbanos "produzem uma força gerativa que seria a causa primordial do desenvolvimento econômico, da inovação tecnológica e da criatividade cultural".

Assim, o urbano aparece como elemento chave para a compreensão do mundo atual, mas não se trata do mesmo urbano de antes, aquele decorrente da materialização das relações sociais e espaciais advindas da revolução industrial. Se trata de um novo conteúdo do urbano e de novas formas de expressão espacial desse fenômeno que se torna mais complexo e se metamorfoseia em um novo processo, o de metropolização (LENCIONI, 2017).

Ferrier (2001) discute em seu texto intitulado "Pour une théorie (géographique) de la métropolisation", elementos que atestam a maior complexidade da realidade territorial contemporânea, observada a partir da crescente presença de aglomerações urbanas no mundo e sugerindo a necessidade de formulação de uma teoria geográfica da metropolização.

Para o autor, se trata de um momento "pós-urbano", mas não porque a urbanização alcançou seu fim, senão porque inaugura-se uma nova era, a das metrópoles, entendidas não apenas em sua dimensão funcional, como centros concentradores das funções superiores ligadas à economia de nosso tempo, como também em razão de sua fabulosa extensão, produzindo uma dinâmica particular e uma morfologia própria.

A metropolização encerraria, assim, a distinção cidade-campo e revelaria a "transformação dos lugares, das condições de vida de seus habitantes, das estruturas da produção de bens e de serviços anunciando uma nova época, uma novidade radical na história da civilização: uma mudança de modernidade" (FERRIER, 2001, p. 42) 
Dentre os elementos constitutivos da teoria da metropolização, o autor ressalta cinco regras básicas, respectivamente: i) aos três componentes do espaço geográfico, a saber, território, territorialização e territorialidade correspondem aos seguintes equivalentes: territórios metropolizados, metropolização e metropolidade (métropolité no original); ii) a metropolização se inscreve em três escalas territoriais: o território da vida cotidiana; o território regional e macro-regional e o território mundo; iii) o conhecimento do território está no âmago dos conceitos e teorias geográficas; iv) são fatores essenciais da metropolização: a mobilidade de pessoas e de bens materiais e imateriais; a diversidade e a dimensão espacial das cidades-territórios produzidas pela metropolização; a maior extensão das bacias de emprego ou seja, das áreas submetidas a uma mesma lógica de mobilidade e atividades econômicas; o alcance da influência cultural, da mídia, de áreas de consumo e de serviços; v) a estreita relação entre metropolização e economia espacial metropolitana.

Como fenômeno irremediável da contemporaneidade, a metrópole como uma forma/função e a metropolização como um processo, está a exigir novas metodologias e bases de dados para apreendê-la e novas terminologias capazes de melhor qualificá-la.

Não é à toa que uma dezena de novas denominações são formuladas, na expectativa de que apreendam a complexa realidade contemporânea. Desse modo, antigos conceitos como o de megalópole são revisitados e atualizados (LANG e KNOX, 2009; LANG e DHAVALE, 2005); outros são formulados, como metápolis (ASCHER, 1995), cidade-região (SCOTT et al, 2001), exópolis e pós metrópoles (SOJA, 2000; 2013), megarregião (SASSEN, 2007), arranjos urbanoregionais (MOURA, 2016). Note-se a importância da região nesses conceitos, isso porque, entende-se que a realidade metropolitana ultrapassa a perspectiva espacial do passado, rumo à constituição de uma região, pela dimensão de sua expressão espacial.

Assim, podemos concluir que o processo de metropolização do espaço não resulta apenas na produção de metrópoles, mas também de uma variedade de novas espacialidades, cuja dinâmica de interação é essencial para sua compreensão. Metodologicamente, a apreensão de tais espacialidades, tem um forte peso dos movimentos pendulares, revelando sua natureza dinâmica.

Como afirma Lencioni (2017, p. 43),

[...] espaços metropolizados são espaços que assumem aspectos e características similares, mesmo que em menor escala, aos da metrópole, quer dizendo respeito aos investimentos de capital, ao desenvolvimento das atividades de serviços com sua correlata concentração e trabalho imaterial, ou, ainda, relacionados ao desenvolvimento das atividades de gestão e administração. Podem, também, apresentar outros aspectos, como a tendência ao desenvolvimento de vários centros comerciais e de serviços, a forma de consumir e viver semelhante à da metrópole, bem como uma densidade significativa de redes imateriais e a presença bastante visível dos socialmente excluídos. [...] Isso significa dizer que podemos encontrar espaços metropolizados fora das metrópoles [...].

Pelo exposto, o olhar sobre o território na contemporaneidade, exige novas lentes interpretativas, mas também novas ferramentas analíticas e novas variáveis. A simples classificação em urbano e rural que no passado era suficiente para distinguir e caracterizar as diferenciações espaciais, já não o é no presente. Parece insuficiente classificar a população a partir de sua condição de habitante urbano e rural, baseada em sua localização fixa em áreas da cidade e do campo. 
Qual é o limite da cidade? É o limite de seu perímetro administrativo? Definitivamente não! Isso não é mais suficiente para entender os espaços que se conformam no presente.

Mas, avançar na interpretação dessa realidade significa igualmente avançar nas bases de informação disponíveis ou mesmo no rearranjo dos dados, em novas possibilidades de agregação que permitam novas leituras e olhares sobre o espaço.

Nesse sentido, parece-nos fundamental ressaltar alguns dos esforços feitos na última década pelo IBGE, oferecendo-nos novas possibilidades de observar as informações, novos agrupamentos e recortes espaciais revisitados. Tais trabalhos encontram-se em consonância com o que tem sido proposto por outras agências similares ao redor do mundo, o que reforça o salutar entrosamento numa rede de agências que se alinham no sentido dos novos produtos e leituras espaciais.

Vejamos um exemplo elucidativo da necessidade de avançar em bases, dados e recortes espaciais, em especial de novas metodologias que devem estar sintonizadas com nosso tempo e com as fontes disponíveis, capazes de capturar as dinâmicas do presente e projetar perspectivas de futuro.

Quando Christaller formulou a Teoria das Localidades Centrais nos anos de 1930, precisou mensurar a influência das cidades sobre o território e utilizou, naquele momento, uma variável que considerou representativa dessa relação de centralidade, como denominou o autor.

Afirmava o autor sobre a problemática da definição da centralidade:

O problema principal era encontrar para este lugar um número que exprimisse seu significado de lugar central. O simples número de habitantes não significa nada existem cidades industriais de 50 ou 100000 habitantes que tem uma influência nula ou quase nula no território ao redor [...]. Eu deveria então tentar de maneira simples converter a qualidade de um lugar - a saber sua capacidade de abastecer uma zona de influência de tamanho e natureza variadas - em uma quantidade equivalente. Para todas as prestações de serviço, é particularmente importante de se comunicar por telefone com a zona de influência [...]. É por isso que escolhi tomar como critério de avaliação da função central de uma ocupação o número de suas conexões telefônicas. (CHRISTALLER, 2005, p. 7-8)

Observa-se, assim, que a metodologia e a variável empregada por Christaller, respondiam à realidade de seu tempo, ou seja, naquele momento da história onde o telefone estava em franco processo de disseminação e correspondia ao que havia de mais moderno e eficiente em termos de comunicação, superando o telégrafo, mensurar as ligações telefônicas significava se aproximar da realidade de fluxos e da comunicação e definir a área de alcance ou influência das cidades.

Portanto, na atualidade, onde as formas de comunicação predominantes não são perpassadas pelas ligações telefônicas, muito embora o aparelho telefônico celular seja uma espécie de "antena" para novas possibilidades de comunicação entre pessoas e empresas, mas a ligação telefônica em sua perspectiva tradicional perde relevância, é preciso também atualizar as formas de mensuração da comunicação.

O estudo do IBGE denominado de REGIC - Região de Influência das Cidades pode ser tomado como um significativo esforço em direção à essa necessária atualização.

O REGIC e seus desdobramentos para a leitura do espaço 
Formulado inicialmente em 1966, o REGIC teve edições nos anos de 1978, 1993 e 2007 e, a edição atual é esperada para publicação em 2020. Ao longo do período em que tem sido realizado, observou as transformações na sociedade e sua metodologia foi se alterando, justamente em razão das necessidades de atualização apontadas anteriormente, variáveis antigas podem ajudar pouco na interpretação da realidade e variáveis novas devem ser incorporadas, muito embora signifiquem desafios do ponto de vista da busca de fontes e da disponibilização de informações.

Tal estudo tem avançado na perspectiva teórica orientadora de suas análises. Assim, como desdobramentos da Teoria das Localidades Centrais, incorpora outra possibilidade analítica, qual seja, aquela proposta por Taylor (2010), External Urban Relational Process: Introducing Central Flow Theory to Complement Central Place Theory, denominada Teoria dos Fluxos Centrais. Tal teoria considera-se que, além das relações advindas das cidades como fornecedoras de bens e serviços, faz-se mister inserir uma outra perspectiva, aquela das relações de longa distância, materializadas nos serviços avançados, nas empresas multilocalizadas e na própria organização das instituições e organismos ligados ao Estado, reconhecendo a tendência de que cidades maiores tenham sua economia comandada por ligações de longa distância.

Assim, novas metodologias se viabilizam, necessariamente, por meio da produção de informações, pelo constante processo de revisão das bases e sua atualização, jamais pela estagnação ou retrocesso.

Como desdobramentos do REGIC, novos agrupamentos regionais foram propostos pelo IBGE, neles, os centros urbanos exercem papel fundamental na definição das lógicas regionais. Tal é o caso do estudo "Regiões de articulação urbana", que reconhece os espaços como "pautados numa organização em rede, onde os centros de gestão do território e os fluxos determinam as vinculações e o arranjo regional" (IBGE, 2013, p. 3).

Assim,

A identificação e delimitação dos novos desenhos regionais, aqui chamadas de Regiões de Articulação Urbana, encontram-se fortemente vinculadas à compreensão das transformações socioespaciais que ocorrem no país e também à maneira como se apreende essas transformações (IBGE, 2013, p. 3).

Nessa perspectiva, de leitura do espaço por meio da gestão desde os centros urbanos, assume que o território brasileiro é composto pelos seguintes níveis escalares na perspectiva regional:

- Regiões Ampliadas de Articulação Urbana: 14 no total e que exercem o papel de comando do território nacional. Tais regiões tem as 12 metrópoles como articuladoras do território, respectivamente, São Paulo, Rio de Janeiro, Brasília, Belo Horizonte, Porto Alegre, Curitiba, Goiânia, Salvador, Recife, Fortaleza, Belém e Manaus, contudo, a elas se somam duas cidades não classificadas como metrópoles no REGIC de 2008 (IBGE, 2008), mas que apresentam relevância na organização de porções ao norte do país, são elas, Porto Velho e Cuiabá. 
Importante salientar que tal configuração regional está associada ao papel efetivo de comando que cada um desses centros urbanos exerce no território, assim, não são os limites político-administrativos que devem nortear os recortes, como mostra a Figura 1.

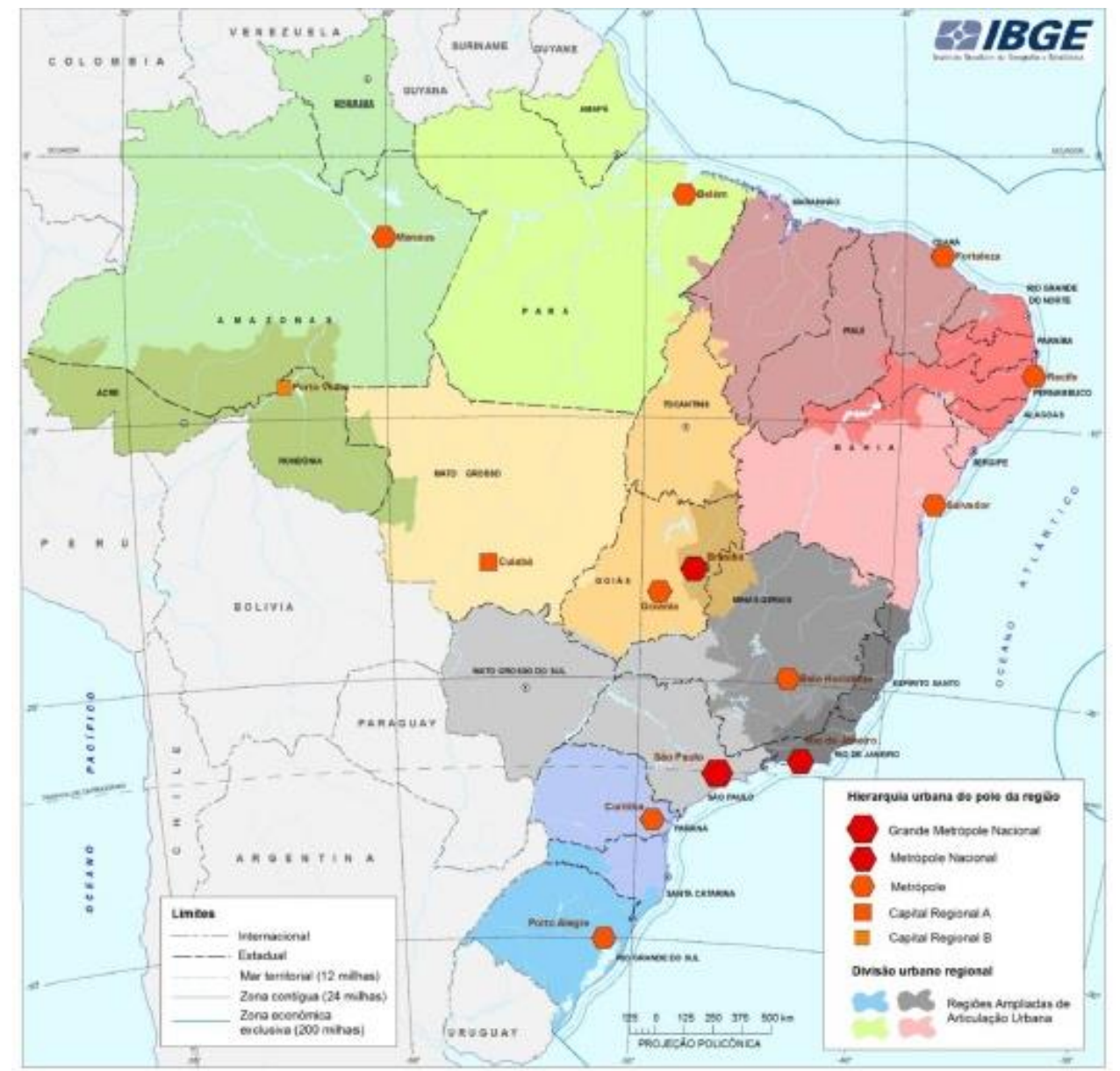

Figura 1. Divisão Urbano Regional - Regiões Ampliadas de Articulação Urbana. Fonte: IBGE (2013, p. 6)

Na Figura 1 podemos verificar que as cores atribuídas a cada recorte regional, não estão contidas nos limites políticos dos estados brasileiros. Note-se, por exemplo, a região ampliada de articulação urbana comandada por Porto Velho, além da totalidade dos territórios estaduais de Rondônia e do Acre, parcelas do Mato Grosso e do Amazonas também são pertencentes a essa região. 
- Regiões Intermediárias de Articulação Urbana: se trata de outro nível escalar, que consiste numa subdivisão do nível anterior e que conforma 161 unidades regionais, que tem como comando cidades classificadas no REGIC como Capital regional A, B e C e Centro sub-regional A. Podem ser caracterizadas como tendo centralidade mediana, por polarizarem um grande número de municípios, possuidores de bens e serviços de alta complexidade, como mostra a Figura 2.

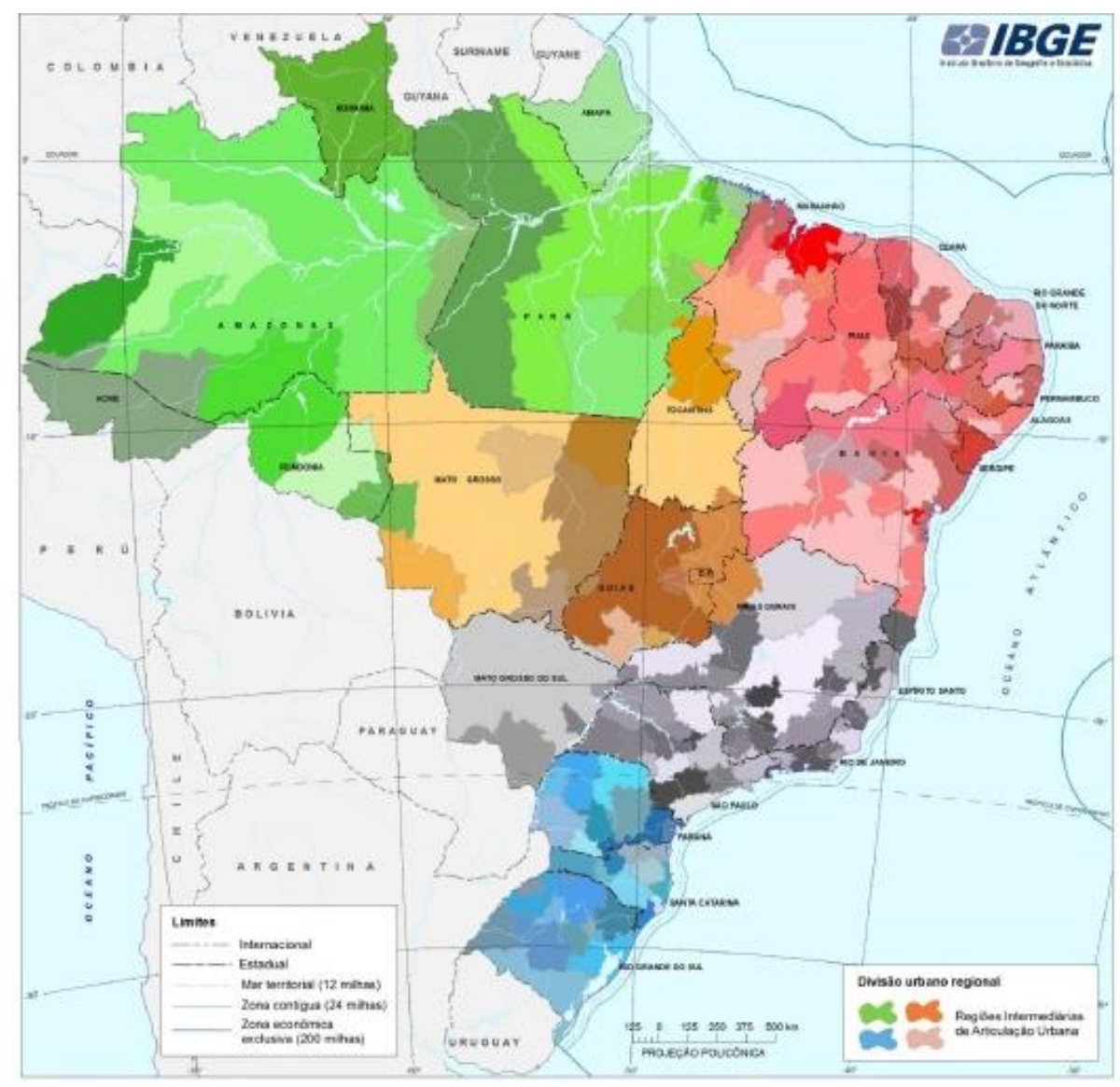

Figura 2. Divisão Urbano Regional - Regiões Intermediárias de Articulação Urbana. Fonte: IBGE (2013, p. 7)

- Regiões Imediatas de Articulação Urbana: comandadas por 482 centros, classificados como Centros sub-regionais e centros de zona, por possuírem centralidades de menor complexidade e, por consequência, oferecerem bens e serviços banais ou de uso/acesso mais frequente, como mostra a Figura 3. 


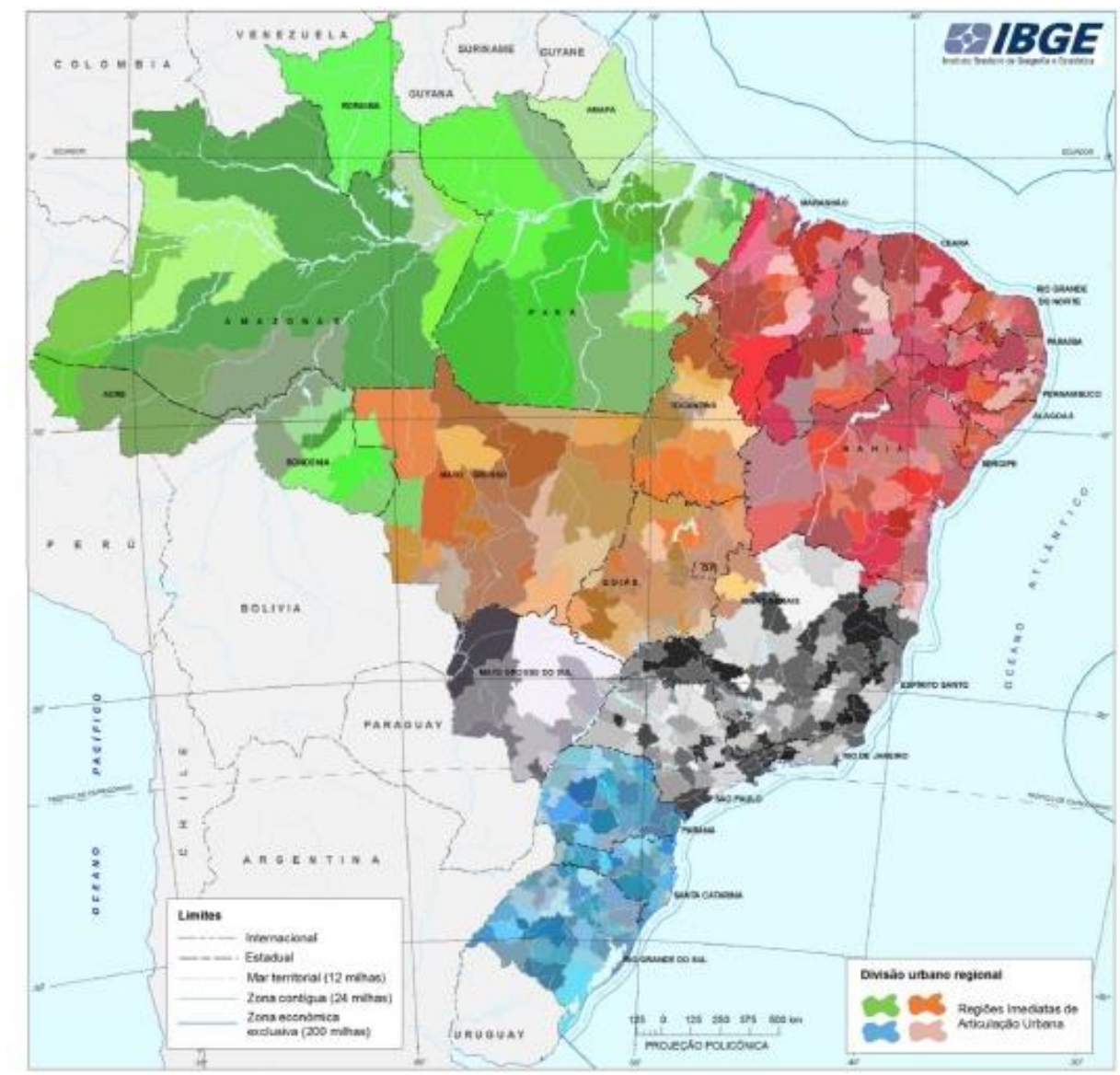

Figura 3. Divisão Urbano Regional - Regiões Imediatas de Articulação Urbana. Fonte: IBGE (2013, p. 8)

Portanto, uma nova possibilidade de olhar o território e suas relações é oferecida a partir dessa classificação.

Contudo, esse nível de organização do território não permite a compreensão dos processos internos a tais recortes, ou seja, define recortes regionais na dimensão interurbana, mas não qualifica a dimensão dos espaços urbano-metropolitanos, seu alcance, suas relações de integração cotidianas, dentre outras. Para fazê-lo, podemos recorrer a outros estudos do IBGE, em especial aquele denominado "Arranjos Populacionais e Grandes Concentrações urbanas no Brasil", que será tratado a seguir.

Arranjos populacionais como possibilidade de apreensão das novas dinâmicas espaciais

A relevância do estudo que trata dos Arranjos Populacionais está no fato de reconhecer que há novas espacialidades para além das metropolitanas, ou seja, tal estudo permite ao pesquisador do tema, coletar elementos que fundamentem a tese da metropolização do espaço, por meio da qual há uma variedade imensa de novas configurações espaciais que, contudo, não podem ser reduzidas ao mesmo tipo, o da metrópole. 
Observamos também, a ausência de uma denominação fechada e rígida, mas a proposição do que se denominou de "arranjo populacional", definido como o "agrupamento de dois ou mais municípios onde há uma forte integração populacional devido aos movimentos pendulares para trabalho ou estudo, ou devido à contiguidade entre as manchas urbanizadas principais" (IBGE, 2015, p.23).

Tais arranjos podem ser de quatro tipos, respectivamente, i) fronteiriços; ii) turísticos e de veraneio no litoral; iii) de até 100 mil habitantes; iv) acima de 100 mil habitantes.

Nota-se três elementos importantes nessa definição: integração, movimento pendular e contiguidade de manchas urbanas. Desse modo, não há dúvida de que temos que atualizar nossas discussões sobre o território e inserir tais elementos como possibilidade explicativa para o momento atual.

Os critérios definidores de um arranjo populacional, foram escolhidos a partir do reconhecimento de que existem importantes relacionamentos cotidianos que envolvem grande parte da população de dois ou mais municípios e o termo integração, foi apontado como o mais apropriado para sintetizar tais relações e contextos (IBGE, 2015).

Dos três critérios apontados como definidores da integração, dois estão diretamente relacionados aos movimentos pendulares para trabalho e estudo, informação coletada e disponibilizada no conjunto das demais produzidas no âmbito do Censo Demográfico, como já ressaltado anteriormente. São elas, a intensidade relativa (correspondendo a 0,25 do índice de integração) e a intensidade absoluta (igual ou superior a 10.000 pessoas entre dois municípios).

O terceiro critério trata da contiguidade das manchas urbanizadas, cujas bordas caracterizadas pela presença de edificações e áreas construídas, devem estar a até $3 \mathrm{~km}$ de distância uma da outra. Segundo o IBGE,

a distância de $3 \mathrm{~km}$ é adotada como máxima por se considerar que, para percorrê-la a pé, demora-se em torno de 30 minutos. Acredita-se que uma distância maior impacta nas relações diárias de convívio, o que não caracterizaria uma integração, ao se considerar somente o critério das distâncias entre as manchas urbanizadas principais (IBGE, 2015, p. 23).

Como resultado dessa metodologia de análise do território, encontramos no Brasil, $294 \mathrm{Ar}$ ranjos Populacionais, que agregavam, segundo o Censo de 2010, 938 municípios, 106.782.428 pessoas ou $55,9 \%$ da população.

Tomando o estado do Paraná como exemplo, temos a Figura 4,. ANela os Arranjos Populacionais demonstram a singularidade em sua distribuição e, além de confirmar essa maior complexidade espacial constituída a partir das maiores cidades do estado, revela também uma variedade de "pequenos" arranjos, que podem passar desapercebidos exatamente por sua dispersão pelo território e por serem capitaneados por cidades que ocupam posições de menor destaque na rede urbana, mas que revelam uma nova dinâmica de integração interna, essencial de ser apreendida para a proposição de ações pelo poder público. 


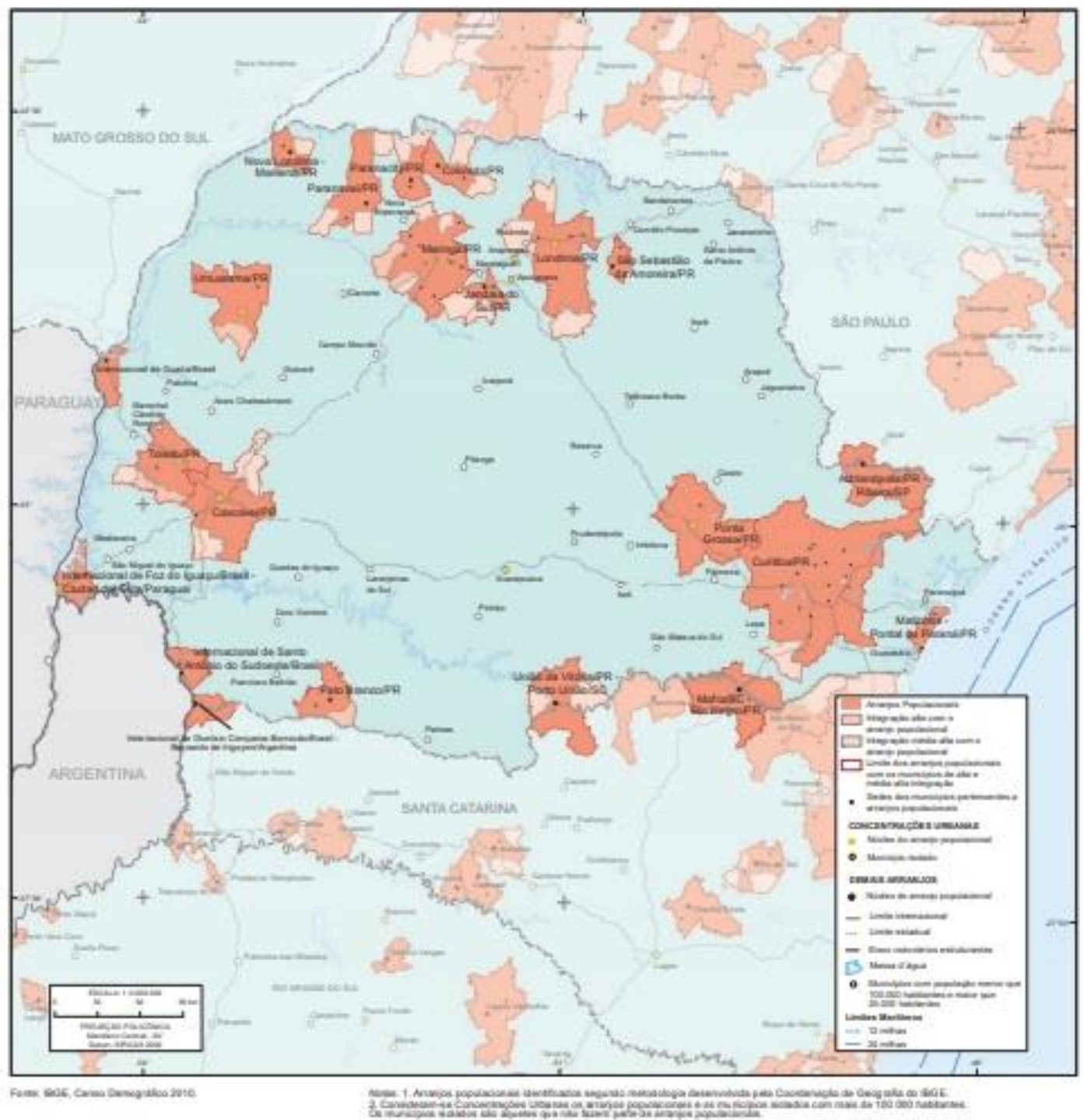

Figura 4. Arranjos populacionais no estado do Paraná. Fonte: IBGE (2015, p.141).

O ganho analítico dessa proposição, reside no fato de permitir constatar que, diferentemente do que ocorria no passado, as políticas públicas para serem efetivas devem, cada vez mais, ser propostas não por e para uma única unidade político-administrativa, mas por e para um outro tipo de conformação, cada vez mais solidária e complementar.

A principal dificuldade está no fato de que os mecanismos institucionais vigentes, ainda são muito incipientes em se tratando de ações supramunicipais, em especial quando os mesmos se dão para além das realidades abrangidas pelas disposições contidas no Estatuto da Metrópole (BRASIL, 2015).

Contudo, a realidade está a nos desafiar em termos da proposição de novas possibilidades não apenas no plano analítico, mas também da intervenção e das ações. 


\section{A multiplicidade de espaços rurais e urbanos}

Outro estudo que merece atenção especial é aquele denominado "Classificação e caracterização dos espaços rurais e urbanos no Brasil” (IBGE, 2017). Também relacionado ao REGIC, nele, a complexidade da realidade é proposta por meio de uma nova tipologia aplicada à condição dos municípios de rural ou urbano, introduzindo uma variedade de situações que devem ser observadas, como mostra a Figura 5.No entanto, a interpretação caiopradiana, ao menos no texto citado, não aborda diretamente outras questões: por que o processo se deu dessa forma? Poderia ter ocorrido de outra maneira? As respostas a tais questionamentos podem ser buscadas, por outro lado, nas interpretações de Sérgio Buarque de Holanda, no texto "O Semeador e o Ladrilhador" (como se sabe, um capítulo da obra "Raízes do Brasil", primeiramente publicada em 1936, quase ao mesmo tempo em que o artigo de Caio Prado que tratamos acima), acerca da mentalidade dos colonizadores.

A tipologia avança em nuances da realidade e apresenta as seguintes possibilidades de enquadramento: i) município predominantemente urbano; ii) município intermediário adjacente; iii) município intermediário remoto; iv) município rural adjacente e v) município rural remoto.

Nesse estudo a qualificação de remoto e adjacente se fez por meio da consideração da relação entre as sedes dos municípios e a presença de meios de transportes como rodovias e hidrovias. O tempo de deslocamento foi calculado desde a sede municipal até as hierarquias propostas no REGIC, respectivamente, metrópole, capital regional e centro sub-regional, como resultado,

Dessa forma, os municípios que estão a uma distância relativa acima da média nacional, simultaneamente, em relação a maiores hierarquias do Regic mais próximas (metrópole, capital regional, centro sub-regional) foram classificados como remotos. Já os municípios cuja distancia for igual ou inferior à média nacional em relação a pelo menos um dos centros Regic considerados foram classificados como adjacentes (IBGE, 2017, p. 54). 


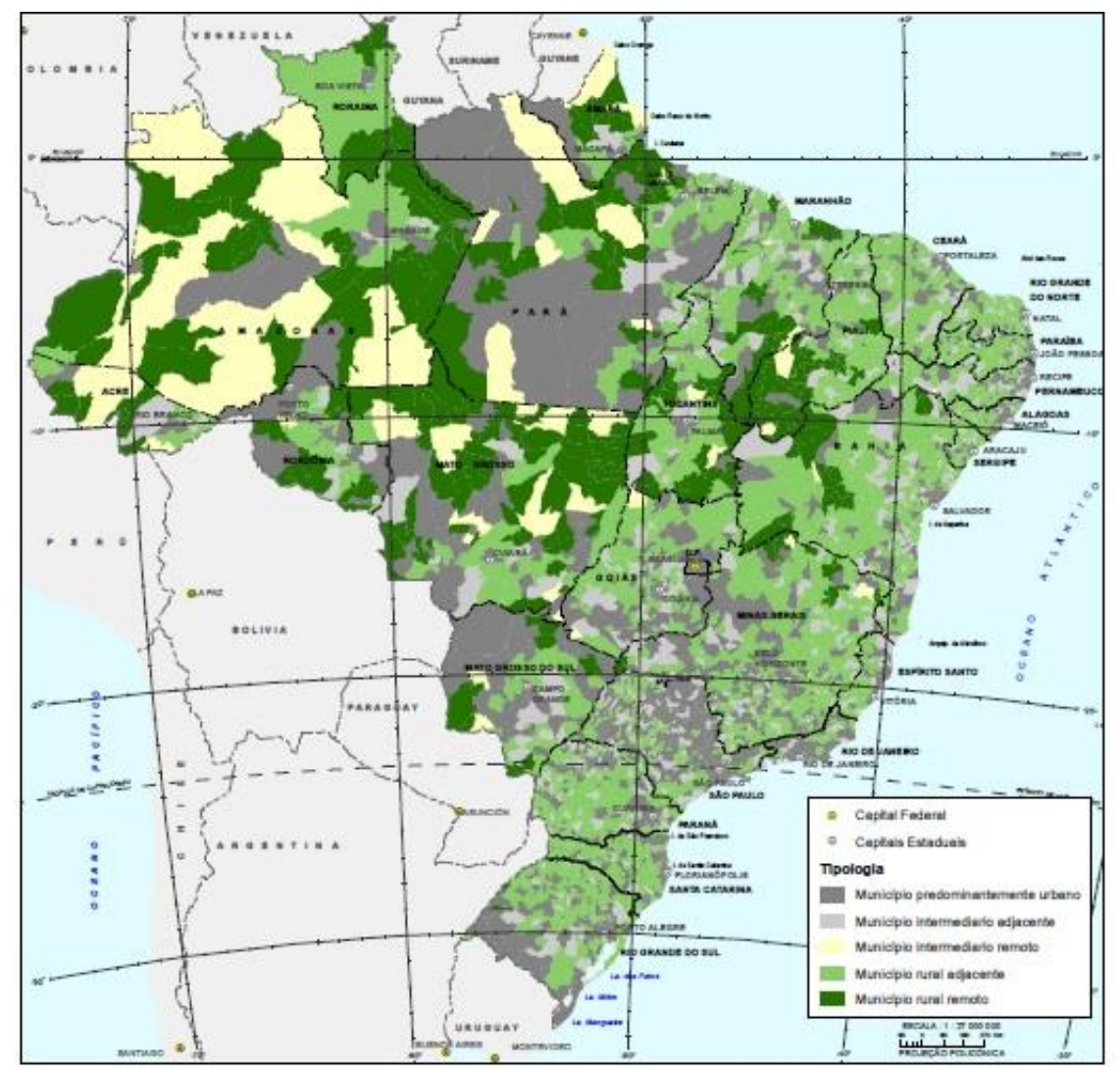

Figura 5. Tipologia municipal rural-urbano.

Fonte: IBGE (2017, p.62).

A Figura 5 permite evidenciar a complexidade de situações verificadas em território nacional, em especial quando se compara o sul e o norte. Se o elemento chave é o tempo de deslocamento, então os casos de rural remoto e intermediário remoto são mais presentes. Cumpre salientar que a área dos municípios no norte do país é significativamente maior que aquela dos municípios do sul, portanto, esse é também um componente para ser inserido na análise.

A Figura 6 mostra um exemplo de classificação tradicional, que conforme apontamos anteriormente, não permite apreender a multiplicidade de situações, uma vez que se baseia no mapeamento das áreas urbanas dos municípios a partir das superfícies construídas e da definição legal dos perímetros urbanos. 


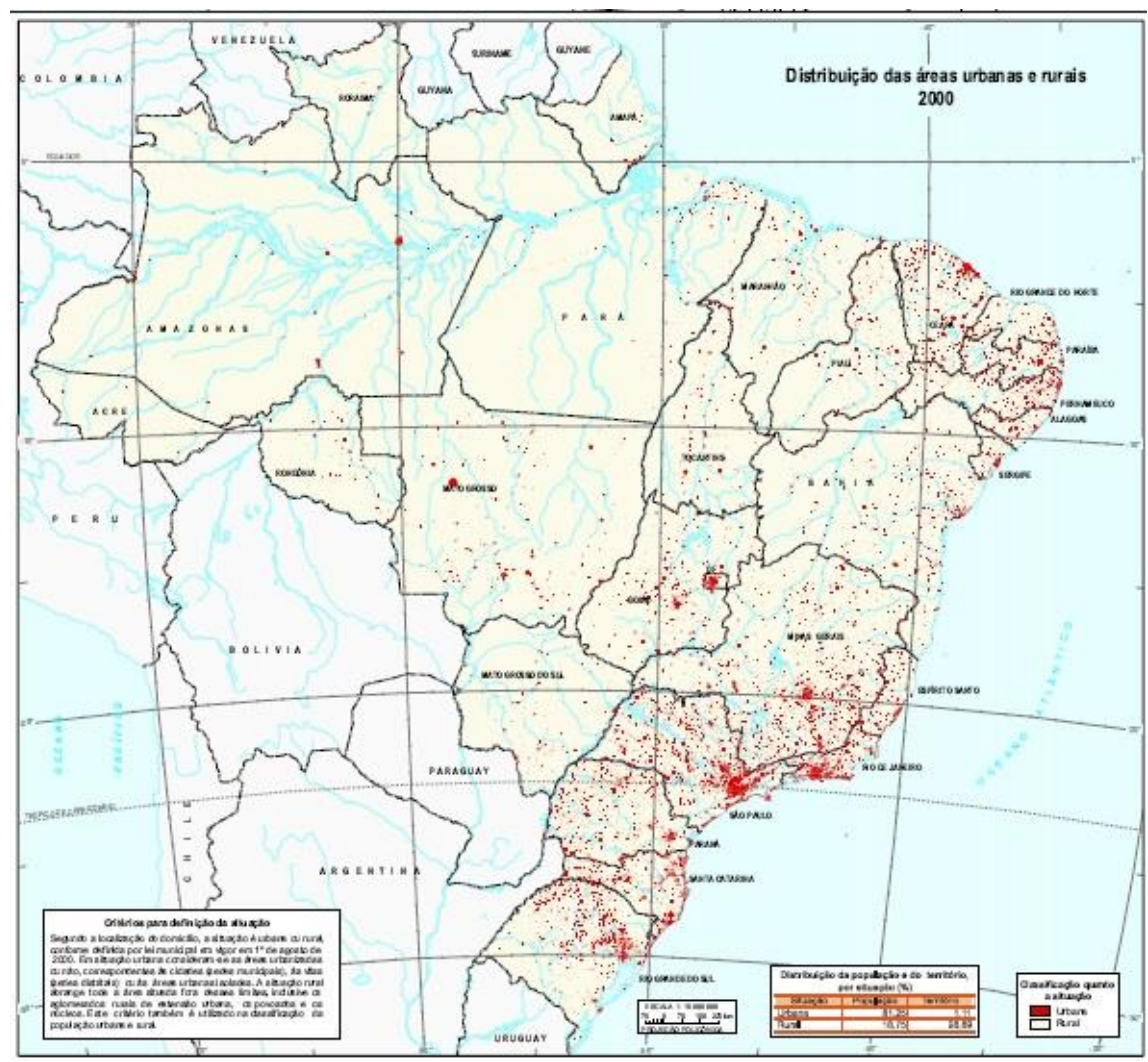

Figura 6. Brasil: áreas urbanas e rurais, 2000

Fonte: IBGE Mapas. Disponível em: <https://mapas.ibge.gov.br/tematicos/demografia>. Acesso em 26/08/2019.

A Figura 5 expressa a possibilidade de maior aproximação com a realidade, superando as classificações binárias (urbano x rural) e propondo uma multiplicidade de situações que melhor permitem revelar as condições dos municípios em particular e de amplas porções do território em geral.

\section{O espaço importa e o IBGE é imprescindível para sua leitura!}

Não se pretendeu fazer um levantamento exaustivo da produção do IBGE, mas pontuar alguns dos estudos desenvolvidos no âmbito dessa instituição e sua importância para a análise da realidade atual, com ênfase nas questões relacionadas ao urbano-metropolitano na atualidade, nosso campo de interesse específico.

Ao disponibilizar esses estudos, dentre outros, o IBGE fomenta o debate entre os pesquisadores, seja acerca da pertinência de suas proposições, seja das metodologias adotadas, além de orientar leituras espaciais em diversos contextos, tanto no acadêmico quanto no campo da administração pública e da iniciativa privada.

A multiplicidade de situações reais está a exigir igualmente a multiplicidade de enfoques analíticos e, não é possível que isso seja feito, sem que haja bases de dados confiáveis, atuais e que permitam o reconhecimento da dinâmica do território no presente e ao longo do tempo. 
Não se pode conceber o avanço da pesquisa e produção do conhecimento sem o inestimável papel do IBGE, oferecendo aos pesquisadores, estudantes e agentes públicos em geral, retratos fieis da realidade. Mas o papel dessa instituição vai além, deve estar sintonizado com o mundo atual e indicar possibilidades de pensar esse mundo no futuro.

O processo de metropolização do espaço requer bases de dados que permitam novos olhares e possam projetar dinâmicas específicas dessa realidade. Se não somos capazes de saber quem somos, enquanto sociedade, quais nossas demandas, fragilidades, carências, onde vivemos e em que condições, se importa ou não os limites administrativos pelos quais circulamos, não seremos capazes de pensar um futuro inclusivo e mais solidário.

O espaço importa! O IBGE é imprescindível na compreensão do espaço! O "G" de Geografia contido no nome dessa instituição não pode ser esvaziado, pelo contrário, deve ser revigorado e fortalecido.

Sem o conhecimento da dinâmica espacial da sociedade brasileira no passado e no presente, será impossível pensar o futuro ou como bem lembrou Milton Santos "Falar sobre o futuro da urbanização e das cidades é coisa temerária. Mas não falar sobre o futuro é deserção. Não se trata do futuro como certeza, porque isso seria desmentir a sua definição, mas como tendência" (SANTOS, 1993, p.117).

\section{Referências}

ASCHER, F. Metápolis ou l'avenir des villes. Paris, Ed. Odile Jacobs, 1995.

BRASIL. Lei n. 13.089/2015. Institui o Estatuto da Metrópole, altera Lei n. 10.257 de 10 de julho de 2001, e dá outras providências. Brasília, DOU. 2015.

CHRISTALLER, Walter. Comment je suis parvenu à la théorie des lieux centraux. Comment une théorie peut naître et comment elle est née dans mon cas: compte-rendu. Cybergeo: Revue Européenne de Géographie [Online], n² 299, 25 janvier 2005. Acesso em 19 de fevereiro de 2013.

FERRIER, Jean-Paul. Pour une théorie (géographique) de la métropolisation. Cahiers de la Métropolisation. Enjeux et définition de la métropolisation, 2001, p. 41-51.

IBGE - INSTITUTO BRASILEIRO DE GEOGRAFIA E ESTATÍSTICA. REGIC - Região de Influência das Cidades 2007. Rio de Janeiro: IBGE, 2008.

. Divisão urbano regional. Rio de Janeiro: IBGE, 2013. Disponível em <https://www.ibge.gov.br/geociencias/cartas-e-mapas/redes-geograficas/15777-divisao-urbanoregional.html?=\&t=o-que-e>. Acesso em 25 março de 2017.

Arranjos populacionais e concentrações urbanas do Brasil. Rio de Janeiro: IBGE, 2015.

Classificação e caracterização dos espaços rurais e urbanos do Brasil: uma primeira aproximação. Rio de Janeiro: IBGE, 2017. 
LANG, R. E.; DHAVALE, D. Beyond Megalopolis: Exploring America's New "Megapolitan" Geography. 2005, p. 1-33. Disponível em <https://digitalscholarship.unlv.edu/brookings_pubs/38/> Acesso em 18 de novembro de 2017.

LANG, R.; KNOX, P. K. The New Metropolis: Rethinking Megalopolis. Regional Studies, v. 43, 2009, p. 789-802.

LENCIONI, S. Metrópole, metropolização e regionalização. Rio de Janeiro: Consequência, 2017.

MOURA, R. Arranjos urbano-regionais no Brasil: uma análise com foco em Curitiba. Rio de Janeiro, Letra Capital, 2016.

SANTOS, Milton. A urbanização Brasileira. São Paulo: HUCITEC, 1993.

SASSEN, S. El reposicionamiento de las ciudades y regiones urbanas en una economía global: ampliando las opciones de políticas y gobernanza. EURE (Santiago), Santiago, v. 33, n. 100, 2007, p. 9-34. Disponível em <https://scielo.conicyt.cl/pdf/eure/v33n100/art02.pdf> Acesso em 10 de março de 2012.

SCOTT, A., AGNEW, J. SOJA, E. e STORPER, M. Cidades-regiões globais. Espaço e Debates: Aliança e competição entre cidades. São Paulo, n. 41, 2001, p.11-25.

SOJA, E. Postmetropolis: critical studies of cities and regions. Oxford, Blackwell Publishing, 2000.

SOJA, E. Para além de postmetropolis. Revista UFMG, Belo Horizonte, v. 20, n.1, 2013, p.136167. 